\title{
A Comparative Study on the Rearing Performance of Six Strains of Eri Silk Worm Samia Ricini, Donovan in Four Different Seasons.
}

\author{
Priyanki Sharma ${ }^{1}$, Jogen Chandra Kalita ${ }^{2}$ \\ Department of Zoology, Gauhati university, Guwahati-14
}

\begin{abstract}
Samia ricini, commonly known as eri silk worm is a domesticated, multivoltine, polyphagous silkworm species which have several morphotypes having distinct morphological differences. This silkworm species is cultured in different regions of North-eastern states specially in Assam. In addition to twenty six different ecoraces, six morphologically distinct strains of Samia ricini have been identified on the basis of larval markings and colour, they are Yellow plain (YP), Yellow spotted(YS), Yellow Zebra(YZ) and Greenish blue plain $(G B P)$, Greenish blue spotted(GBS), Greenish blue zebra(GBZ).The present study was conducted with the aim to evaluate the rearing performance of these six strains of eri silk worm in four different seasons. To achieve this goal Fecundity, Hatching percent, Effective rate of rearing, larval duration and moth emergence and Shell ratio(\%) were evaluated in spring, summer, autumn and winter. The study reported significant differences in all these parameters among different strains. The variation among them was significant at $P$ $<0.05$ significant level. Seasonal variation also have profound effect on these parameters. Summer and winter seasons were reported as unfavorable in terms of performance while spring and autumn can be considered more suitable. Present study revealed that Yellow spotted strain showed highest shell ratio (\%) therefore expected to produce more silk. ERR and hatching(\%) was highest in GBP and GBS showed highest fecundity in autumn followed by spring. Larval duration was longest in GBS in winter and lowest in GBP in summer. The results revealed that Greenish blue strains -GBP and GBS are better in terms of rearing performance and spring and autumn are the favorable seasons for rearing of all six strains.
\end{abstract}

Keywords: Strains, ecoraces, fecundity, hatching, Effective rate of rearing

\section{Introduction}

Sericulture is the part and parcel of cultural heritage of the people in North east India. This region is the home of many sericigenous insects and their food plants. Assam is the only state of India blessed with large variety of silkworm species out of which four are cultured in this part. Out of these Eri silk worm, Samia ricini is the fully domesticated non-mulberry or vanya silk which is also called as Ahimsa silk. Samia ricini is a polyphagous, multivoltine silkworm cultured usually by the rural people as off season occupation in different parts of North eastern states of India. There are twenty six ecoraces of Samia ricini distributed in different parts of north east India and six homozygous strains which can be identified by their larval markings and color. They are-Greenish Blue Plain (GBP), Greenish Blue spotted(GBS), Greenish Blue Zebra(GBZ), Yellow Plain(YP), Yellow Spotted(YS), Yellow Zebra(YZ).(Debraj et al.,(2001). Several ecoraces of Samia ricini were screened using their morphological charcters, growth, yield and by genetic markers and significant variation was found among them.(Duanpen et al.,2015; Sarkar, 2013 ).Studies revealed that populations of commercially exploited eri silk worms found in different regions of northeast India showing wide variations in their morphological and quantitative characters such as absolute silk content, larval weight, cocoon weight,ocoon shell weight and shell ratio (Siddiqui et al., 2000). The study of ecoraces on different seasons also showed variation in growth, rearing performances as well as cocoon parameters. Many studies have been performed by various authors to identify superior ecoraces having both quality and quantity economic characters (Sarkar et al.,2013; Ray et al.,2011). The classification and characterization of silkworm strains are also important as for development of new hybrids and for selecting promising strain for hybridization programs. An extensive study is needed for the improvement of existing strains of Samia ricini for commercial production of silk and to produce new improved strain through different breeding programs to improve silk productivity and also increase the strains adaptability to different environmental condition and also to produce disease resistant variety (Sen et al.,1999). A few fragmentary studies have been conducted to evaluate variation among these strains using morphological parameters, productivity, rearing performances as well as biochemical and molecular markers (Singh et al.,2011; Wankhade et al.,2014). But the complete data on all six strains, their morphometrics, economic parameters are almost lacking. Cross-breeding strategies have been extensively used as a means of harnessing heterosis in the silkworm. It has been shown that parental homozygosity also known as genetic purity of a strain has distinct influence on the degree of manifestation of heterosis (Nagaraju and Goldsmith,2002). 
Temperature plays a vital role on the growth of the silkworms. As the silkworms are cold blooded animal temperature have a very direct effect on various physiological activities of them. A very wide fluctuation is very harmful to the development of the silkworm. Therefore effects of temperature should be considered during silkworm study. Very high or very low temperature and humidity always gives poor results in silkworm culture. The temperature of $25^{\circ} \mathrm{c}$ and humidity of 75 is optimum to get the best results. Therefore performance of different strains on different seasons should be evaluated to determine the effects of seasonal variations and the adaptability of the strains ( Rahmathulla et al., 2013). Though a few studies have been done on the effect of temperature and humidity in Samia ricini but no work has been reported regarding the effects seasonal variation on different strains of Samia ricini. The productivity and quality in sericulture depends on the rearing performances of the silkworm and environmental conditions. Keeping this in mind here in this study rearing performances of six strains was considered along with the environmental factors like temperature and humidity.

The present study is aimed at the evaluation of rearing performances of six different strains of Samia ricini, Donovan in four different seasons and to fulfill this aim, following objectives were undertaken-

1. Evaluation of larval duration of six strains on four different seasons

2. Evaluation of Fecundity of six strains in four different seasons

3. Evaluation of Hatching (\%) of six strains in four different seasons

4. Evaluation of Effective rate of rearing (ERR \%) of six strains in four seasons.

5.Evaluation of Moth emergence $(\%)$ in six strains in four seasons.

6. Evaluation of cocoon shell ratio (\%) of six strains in four seasons.

\section{Materials And Methods}

The present investigation involves collection, rearing, characterization of different eri silk strains for evaluation of superior variety. To carry out the present investigation the seeds (eggs) of eri silkworm were collected in the month of May 2011 from the directorate of sericulture, Khanapara. They provided the eggs from different regions like Borduar, Jagiroad (topatoli), Boko and Mangaldoi.They had assured me of having all the strains in those eggs. After collecting the disease free layings (DFL) the eggs were brought to the seri-biotech laboratory of Nowgong College, Nagaon where the rearing of the silkworms was conducted for successive generations. The six strains were named as-Greenish blue plain-GBP, Greenish blue spotted-GBS, Greenish blue zebra -GBZ and Yellow Plain-YP, Yellow Spotted -YS and Yellow Zebra-YZ.

After segregation of each strain into different trays in $5^{\text {th }}$ instar on the basis of body colour and marking ,each strain were cultured for eight consecutive generations to get the pure line strain. After achieving pure line different rearing parameters were selected for consideration. Data were recorded for four seasons they are-Spring (March-May), summer June -August), autumn (Sept-Nov) and winter (Dec-Feb). Temperature and humidity were recorded daily. Proper care was taken to avoid intermixing as well as cleanliness was maintained to prevent occurrence of diseases. Different studies were carried out in the Biotech-hub, Department of Botany, Nowgong College All the data were analyzed using SPSS version 18 by one way analysis of variance (ANOVA, LSD test) to test the significance of variation in different parameters among different strains of eri silk worm at $\mathrm{P}<0.05$ significance level.

\section{Calculation of the fecundity:}

Fecundity, Effective rate of rearing (ERR) is calculated for each generation for each strain. To study the fecundity, pairs of freshly emerged moth were placed in khorika. For each strain, the two replications four pairs of moths kept in plastic baskets so that there is no mixing of moths of different strains. The moths of each strain were decoupled after three hours and female moths were allowed to lay eggs on khorika. After three days the eggs were separated from khorika counted replication wise to find out the fecundity and recorded as numbers egg per female. Mean value is then calculated for each strain .

Hatching (\%):

Hatching is a very important character for rearing and crop harvest. Hatching (\%) is calculated by the following expression:

$$
\text { Hatching }(\%)=\frac{\text { No of eggs hatched }}{\text { No of eggs kept for brushing }} \times 100
$$

Calculation of Effective rate of rearing (ERR): The effective rate was calculated by counting the number of larvae brushed for the cocooning and number of cocoon yield using the following formula: 


$$
\begin{aligned}
& \text { No. of cocoon yield } \\
& \text { ERR: ---------------------------------× } 100
\end{aligned}
$$

ERR is important for silk worm rearing as it is a useful parameter to determine the amount of silk to be spanned. More ERR means more productive cocoon that is more silk.

Moth emergence: The emergence of moth from maximum cocoons indicates healthy rearing process. Selection of good cocoons is very important to get healthy moths with healthy reproductive behavior.

$$
\begin{gathered}
\text { Moth emergence }(\%)=\text { Number of moth emerged } \\
\text { Number of cocoons kept for moth } \\
\text { Emergence }
\end{gathered}
$$

Shell ratio(\%): Shell ratio was calculated from the following formula.

Weight of the cocoon shell

Shell $\operatorname{ratio}(\%)=$

Weight of the whole cocoon

\section{Results}

The experimental findings of the present investigations on rearing performance of six strains of eri silk worm Samia ricini Donovan have been presented here in tabulated form along with statistical

\begin{tabular}{|c|c|c|c|c|c|}
\hline Strains & Spring & Summer & Autumn & Winter & \multirow{7}{*}{$\begin{array}{l}\text { Seasons: } \\
\mathrm{F}=151.937^{*} \\
\text { ANOVA, LSD test, } \\
\mathrm{P}<0.05 \text { significant } \\
\text { level) }\end{array}$} \\
\hline GBP & $20.00 \pm 2.64 a$ & $18.25 \pm 1.04 \mathrm{~b}$ & $25.50 \pm 3.72 \mathrm{c}$ & $35.00 \pm 1.73 \mathrm{~d}$ & \\
\hline GBS & $22.00 \pm 2.65 \mathrm{a}$ & $21.75 \pm 2.80 b$ & $23.25 \pm 2.63 \mathrm{c}$ & $36.71 \pm 1.49 \mathrm{~d}$ & \\
\hline GBZ & $21.50 \pm 1.81 \mathrm{a}$ & $20.25 \pm 2.76 b$ & $25.43 \pm 2.11 \mathrm{c}$ & $35.29 \pm 1.68 \mathrm{~d}$ & \\
\hline YP & $22.25 \pm 1.15 \mathrm{a}$ & $20.65 \pm 4.56 b$ & $25.28 \pm 6.04 \mathrm{c}$ & $36.25 \pm 1.16 \mathrm{~d}$ & \\
\hline YS & $21.38 \pm 1.13 \mathrm{a}$ & $18.70 \pm .995 b$ & $24.34 \pm 2.74 \mathrm{c}$ & $35.50 \pm 4.40 \mathrm{~d}$ & \\
\hline $\mathrm{YZ}$ & $21.25 \pm .901 \mathrm{a}$ & $19.85 \pm .818 b$ & $23.63 \pm 2.06 \mathrm{c}$ & $36.33 \pm 4.04 d$ & \\
\hline
\end{tabular}
analysis.

Larval duration: It is the time from hatching of the worm upto the end of the $5^{\text {th }}$ instar.

Table 1: Larval duration of six strains of Samia ricini in four different seasons (days)

The values are mean \pm SD. The different letters in the columns indicate significant differences and same letter indicates non-significant values at $\mathrm{P}<0.05$ significant level.(*significant difference)

The statistical analysis revealed that there was significant variation in larval duration in different seasons but larval duration has no significant variation among the six strains.

The results represented were the mean values of the data collected for two consecutive years. The result showed that season had a significant impact on the larval duration in case of all the strains. The larval duration recorded highest in winter and lowest in summer and followed by spring irrespective of the strain. Longest larval duration was recorded in GBS ( 36.75 days) in winter while shortest recorded in GBP (18.25) in summer. In spring and

\begin{tabular}{|c|c|c|c|c|c|}
\hline STRAINS & Spring & summer & autumn & winter & \multirow{7}{*}{$\begin{array}{l}\text { Seasons: } \\
\mathrm{F}=18.202^{*} \text {,ANOVA, LSD } \\
\text { Test, } \mathrm{P}<0.05 \text {. } \\
\text { Strains: } \\
\mathrm{F}=5.987 * \text { ANOVA, LSD } \\
\text { test, at } \mathrm{P}<0.05 \text { significant } \\
\text { level }\end{array}$} \\
\hline GBP & $410 \pm 11.136 \mathrm{~b}$ & $397.66 \pm 46.808 \mathrm{c}$ & $412.33 \pm 4.58 \mathrm{a}$ & $402.33 \pm 4.933 a$ & \\
\hline GBS & $449 \pm 13.892 a$ & $408.33 \pm 2.517 \mathrm{a}$ & $454 \pm 12.49 \mathrm{~b}$ & $400.67 \pm 12.14 a$ & \\
\hline GBZ & $405.66 \pm 12.345 c$ & $373.33 \pm 11.136 b$ & $407 \pm 5.00 \mathrm{a}$ & $390.33 \pm 7.00 \mathrm{~b}$ & \\
\hline $\mathrm{YP}$ & $439.33 \pm 4.359 a$ & $403.33 \pm 3.606 a$ & $435 \pm 7.638 b$ & $403.44 \pm 20.05 a$ & \\
\hline YS & $442.66 \pm 3.606 \mathrm{e}$ & $402.33 \pm 2.646 a$ & $441 \pm 5.508 b$ & $373.33 \pm 11.136 \mathrm{ab}$ & \\
\hline $\mathrm{YZ}$ & $425.66 \pm 13.115 \mathrm{ab}$ & $400.66 \pm 51.029 a$ & $454 \pm 14.107 b$ & $392.66 \pm 11.136 c$ & \\
\hline
\end{tabular}
summer the larval durations were shorter than in autumn and winter. There was no significant difference in the larval duration among six different strains of eri silk worm.

Table 2: Fecundity of six strains of Samia ricini in four different seasons (nos.) 
The values are mean \pm SD. SD is followed by same letter within column are not significantly different but with different letters are significantly different at $\mathrm{P}<0.05$ significant level. (*significant difference)

Fecundity: The comparison of fecundity of different strains showed the following order-

$\mathrm{GBS}>\mathrm{YP}>\mathrm{YS}>\mathrm{YZ}>\mathrm{GBP}>\mathrm{GBZ}$.

GBS showed highest fecundity, in autumn (454) followed by spring (449). Results revealed that spring and autumn recorded higher fecundity while summer and winter season showed comparatively lower fecundity in all six strains. The statistical analysis showed that there was significant variation in fecundity among different strains .It has been revealed from the results that fecundity of different strains was significantly affected by seasonal variation.

Table 3: Hatching \% of six different strains of Samia ricini in four different seasons:

\begin{tabular}{|c|c|c|c|c|c|}
\hline STRAINS & SPRING & SUMMER & AUTUMN & WINTER & \multirow{7}{*}{$\begin{array}{l}\text { Season-F=65.03*, } \\
\text { ANOVA,LSD test at } \\
\text { P }<0.05 \% \text { significant level }\end{array}$} \\
\hline GBP & $85.00 \pm 5.65 a$ & $64.48 \pm 2.89 \mathrm{c}$ & $88 \pm 2.45 \mathrm{ad}$ & $63.93 \pm 1.07 \mathrm{c}$ & \\
\hline GBS & $81.00 \pm 2.31 \mathrm{~b}$ & $73.52 \pm 3.03 \mathrm{ab}$ & $81 \pm 2.56 \mathrm{~b}$ & $61.25 \pm 2.06 \mathrm{c}$ & \\
\hline GBZ & $80.24 \pm 1.56 \mathrm{~b}$ & $68.6 \pm 5.06 \mathrm{~d}$ & $85 \pm 1.34 \mathrm{c}$ & $67.43 \pm 2.87 \mathrm{ab}$ & \\
\hline$\overline{\mathrm{YP}}$ & $83.00 \pm 3.43 \mathrm{c}$ & $70.96 \pm 3.12 \mathrm{~d}$ & $81.8 \pm 2.54 b$ & $63.5 \pm 6.02 \mathrm{c}$ & \\
\hline YS & $84.00 \pm 2.78 \mathrm{a}$ & $65.67 \pm 2.21 \mathrm{c}$ & $83.9 \pm 1.23 \mathrm{~b}$ & $65.41 \pm 3.21 \mathrm{c}$ & \\
\hline $\mathrm{YZ}$ & $81.71 \pm 2.33 \mathrm{~b}$ & $62.5 \pm 1.13 \mathrm{c}$ & $79.29 \pm 1.04 \mathrm{~b}$ & $65.81 \pm 2.13 \mathrm{c}$ & \\
\hline
\end{tabular}

The values are mean \pm SD. *significant difference at $\mathrm{P}<0.05 \%$ significant level.(*significant difference)

The statistical analysis reveals that there is significant variation in Hatching percent (\%) among different strains and seasons. The statistical analysis showed significant variation in Hatching \% in different seasons. There was significant differences in hatching (\%) among different strains. In spring and autumn GBP recorded highest hatching\% followed by YS. The results revealed that in spring and autumn hatching \% was more than winter and summer irrespective of the strains.

Table 4: ERR (\%) of the six strains of Samia ricini in four different seasons

\begin{tabular}{|c|c|c|c|c|c|}
\hline strains & Spring & Summer & Autumn & Winter & \multirow{7}{*}{$\begin{array}{l}\text { Season: } \\
\text { F=4.285* ANOVA } \\
\text { LSD test at } P<0.05 \\
\text { significant level. } \\
\text { Strains: } \\
\text { F=.526 ANOVA, } \\
\text { LSD test at P<.05 } \\
\text { significant level. }\end{array}$} \\
\hline GBP & $94.7 \pm 3.12 a$ & $86.3 \pm 7.40 b$ & $95.2 \pm 13.32 \mathrm{c}$ & $84.2 \pm 2.64 \mathrm{~d}$ & \\
\hline GBS & $88.9 \pm 9.10 \mathrm{a}$ & $85 \pm 12.49 \mathrm{~b}$ & $92 \pm 14.00 \mathrm{c}$ & $82.6 \pm 5.46 \mathrm{~d}$ & \\
\hline GBZ & $91.3 \pm 7.47 \mathrm{a}$ & $85.1 \pm 2.05 \mathrm{~b}$ & $90.4 \pm 3.73 \mathrm{c}$ & $82.7 \pm 2.74 \mathrm{~d}$ & \\
\hline YP & $90.4 \pm .89 \mathrm{a}$ & $82 \pm 3.60 \mathrm{~b}$ & $90.6 \pm 10.34 \mathrm{c}$ & $83.4 \pm 4.21 \mathrm{~d}$ & \\
\hline YS & $92.7 \pm 2.04 \mathrm{a}$ & $84.6 \pm 18.19 \mathrm{~b}$ & $92.06 \pm 1.15 \mathrm{c}$ & $82 \pm 8.7 \mathrm{~d}$ & \\
\hline $\mathrm{YZ}$ & $88.9 \pm 7.4^{\mathrm{a}}$ & $86.2 \pm 3.60^{b}$ & $91.2 \pm 2.00^{c}$ & $83.2 \pm 5.29^{d}$ & \\
\hline
\end{tabular}

The values are mean \pm SD. The different letters in the columns indicate significant differences and same letter indicates non-significant values at $\mathrm{P}<0.05$ significant level. (*significant difference)

Highest ERR was found in GBP (95.2) in autumn. It's indicated better survival rate of this strain. It was followed by YS (92.7\%) and YS followed by GBS (92\%).

The results revealed that there was significant difference in ERR in different seasons. But there is no significant differences in ERR among different strains. Autumn and spring can be considered better in terms of ERR than winter and summer. The order of ERR of six strains:

GBP $>$ GBZ $>$ YZ $>$ GBS $>$ YP $>$ YS.

Table 5: Moth emergence (\%) in six strains of Samia ricini in four different seasons.

\begin{tabular}{|c|c|c|c|c|c|}
\hline Strains & Spring & Summer & Autumn & Winter & \multirow{8}{*}{$\begin{array}{l}\text { Season: } \\
\text { F-11.96*, ANOVA } \\
\text { at } \mathrm{P}<0.05 \\
\text { significant level. }\end{array}$} \\
\hline GBP & $93 \pm 1.41^{\mathrm{b}}$ & $90.5 \pm .707^{\mathrm{a}}$ & $93.5 \pm .707^{\mathrm{b}}$ & $88.5 \pm .707^{\mathrm{a}}$ & \\
\hline GBS & $94 \pm 1.41^{\mathrm{a}}$ & $90.5 \pm .707^{\mathrm{a}}$ & $92.5 \pm .707^{\mathrm{a}}$ & $89.5 \pm .876^{\mathrm{a}}$ & \\
\hline GBZ & $92.5 \pm .707^{\mathrm{b}}$ & $88 \pm 1.32^{\mathrm{b}}$ & $92 \pm 1.41^{\mathrm{a}}$ & $88.5 \pm 2.12^{\mathrm{a}}$ & \\
\hline YP & $91 \pm .1 .41^{\mathrm{c}}$ & $88 \pm 1.40^{\mathrm{b}}$ & $91.5 \pm .707^{\mathrm{c}}$ & $89 \pm .655^{\mathrm{a}}$ & \\
\hline YS & $93.5 \pm .707^{\mathrm{b}}$ & $90.5 \pm .70^{c}$ & $94.5 \pm .707^{b}$ & $92.5 \pm .707^{\mathrm{b}}$ & \\
\hline YZ & $92.5 \pm .707^{\mathrm{b}}$ & $91 \pm 1.23^{\mathrm{c}}$ & $92.5 \pm 1.34^{\mathrm{a}}$ & $89.5 \pm 1.41^{\mathrm{a}}$ & \\
\hline F-value & $3.31^{*}$ & $3.8^{*}$ & 1.84 & $4.13 *$ & \\
\hline
\end{tabular}


Values are mean \pm SD. The SD followed by different letters indicates significant difference and same letter indicates non-significant at $\mathrm{P}<0.05 \%$ level of significance. $(*$ significant difference)

One way analysis of variance revealed that there was significant difference in moth emergence in different seasons.Significance difference was found among six different strains of Samia ricini in each season except in autumn.

The result revealed that moth emergence was highest in spring and autumn while comparatively lower in summer and winter crops. Highest moth emergence was reported in autumn in YS strain (94.5\%) followed by GBS in spring $(94 \%)$.

Table 6: Shell ratio (\%) of six strains of Samia ricini in four different seasons.

\begin{tabular}{|c|c|c|c|c|c|}
\hline strains & spring & summer & autumn & winter & \multirow{7}{*}{$\begin{array}{l}\text { Strains, }: F=4.286^{*} \\
\text { ANOVA,LSD test } \\
\text { at } P<0.05 \text { level, } \\
\text { Season:F=28.450*, } \\
\text { ANOVA, LSD test } \\
\text { atP<0.05\% } \\
\text { significant level. }\end{array}$} \\
\hline GBP & $13.98 \pm .98 \mathrm{a}$ & $11.2 \pm 1.08 \mathrm{p}$ & $14.59 \pm 1.50 \mathrm{ab}$ & $11.25 \pm .250 \mathrm{a}$ & \\
\hline GBS & $14.74 \pm 2.75 c$ & $13.59 \pm 1.41 \mathrm{c}$ & $14.53 \pm 3.52 \mathrm{ab}$ & $11.42 \pm 1.43 \mathrm{a}$ & \\
\hline GBZ & $14.00 \pm 1.00 \mathrm{~d}$ & $10.80 \pm .482 \mathrm{ab}$ & $12.89 \pm .870 \mathrm{a}$ & $10.47 \pm 1.51 b$ & \\
\hline YP & $13.53 \pm .545 \mathrm{e}$ & $11.41 \pm 295 \mathrm{a}$ & $13.72 \pm 415 \mathrm{a}$ & $11.27 \pm 1.27 \mathrm{a}$ & \\
\hline YS & $16.03 \pm 1.005 b$ & $12.23 \pm .206 \mathrm{~b}$ & $15.87 \pm 913 b$ & $12.10 \pm 2.05 \mathrm{a}$ & \\
\hline $\mathrm{YZ}$ & $13.34 \pm 1.53 \mathrm{e}$ & $10.6 \pm .680 \mathrm{a}$ & $14.41 \pm 1.40 \mathrm{ab}$ & $11.41 \pm 1.4 \mathrm{a}$ & \\
\hline
\end{tabular}

Values are mean \pm SD. The SD followed by different letters indicates significant difference and same letter indicates non-significant at $\mathrm{P}<0.05 \%$ level of significance. (*significant difference)

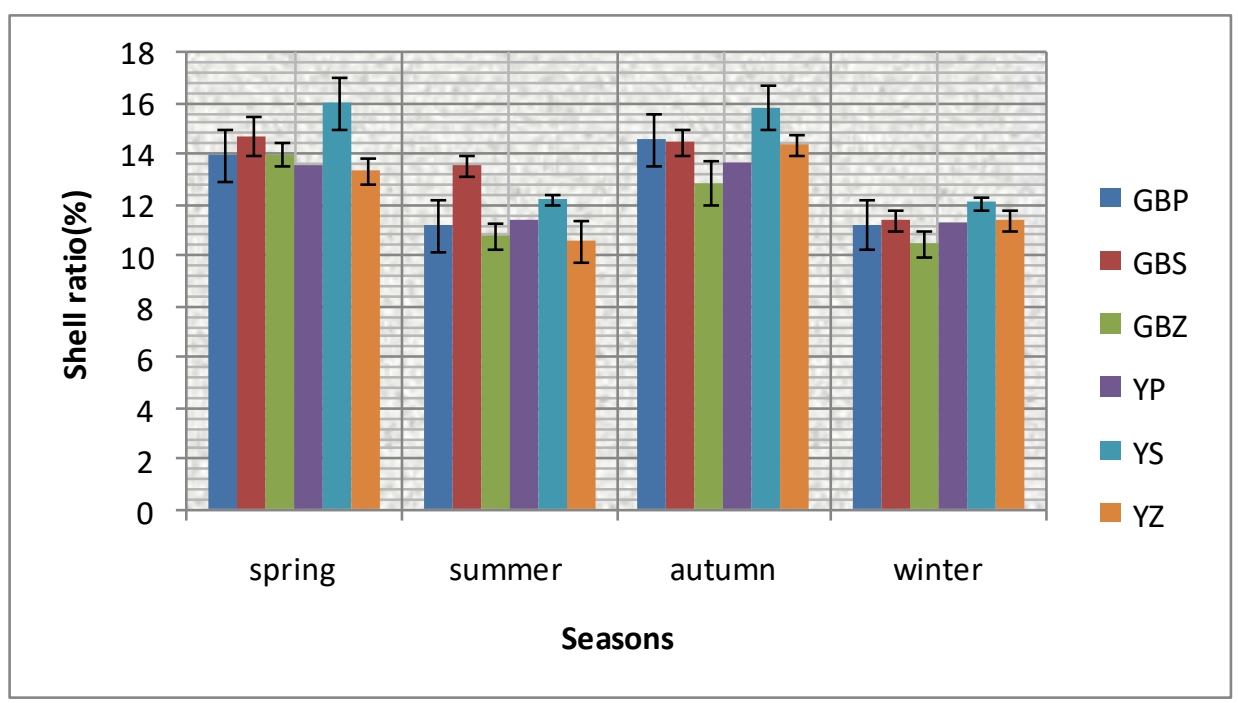

Fig 1: Shell ratio (\%) of six strains of Samia ricini in four different seasons. Error bars represents Standard deviation $( \pm \mathrm{SD})$.

There was significant difference in the shell ratio among six strains of eri silk worms at $\mathrm{P}<0.05 \%$ significant level and the Yellow spotted (YS) recorded the highest shell ratio followed by Greenish Blue spotted (GBS). The Yellow spotted reported to have highest shell ratio in Spring (16.03\%). The arrangement from highest to lowest shell ratio- $Y S>$ GBS $>$ GBP $>Y P>Y Z>G B Z$. Shell ratio of different strains were significantly different in different seasons.

\section{Discussion And Conclusion:}

The experimental findings of the present study revealed significant variation in economic parameters of six different eri silkworm strains. The significant variation in rearing parameters were found in respect to 
different seasons. The present study revealed that autumn and spring were suitable seasons for silkworm rearing as all six strains showed short larval duration with more fecundity and hatching percent with highest ERR in these two seasons. Shell ratio (\%) was also reported high in these two seasons. On the other hand Summer and winter recorded less productivity, which may be due to low rate of feeding in high or very low temperature or low food conversion efficiency by these silkworms. Effective rate of rearing indicates the survivability of silkworm during the silkworm crop. Significant differences was observed in ERR in different seasons but no significant difference was observed in ERR among different strains. This present study showed highest ERR in GBP $(95.2 \%)$ in autumn followed by GBP(94.7) in spring and this finding can be supported by the findings of Chakravorty and Neog et al., ( 2006 ) as they got similar result. The better rearing condition with better variety silkworm leads to higher fecundity by silkworm moths. The present study recorded highest fecundity in Greenish blue spotted (GBS, 454nos) in autumn and followed by spring (449nos). The earlier work by Chakravorty and Neog et al., (2006) reported almost similar result with highest fecundity in YP and GBS. This work supports the present finding and GBS can be utilized as better strain in terms of fecundity to get highest yield from rearing. Hatching percent is also an important parameter for consideration as actual yield to a great extent depends upon it. Wankhde et al., (2014) reported highest hatching percent in YP whereas in present study hatching percent was found highest in $\operatorname{GBP}(88 \pm 2.45)$ in autumn followed by GBZ $(85 \pm 1.34)$ in autumn. Shell ratio was highest in YS (16.03\%) in Autumn and then in spring . Least shell ratio was found in GBP in summer. In all the strains the lowest shell ratio was found in winter and summer. Therefore rearing of silkworm in those seasons can be considered less productive. From the above results Greenish strains were recorded better in terms of fecundity, hatching, ERR and Yellow spotted was reported better in terms of cocoon quality. But further detail study will be required to establish a particular strain as best by evaluating all morphometric, economic ,cocoon as well as genetic characteristics. From the present findings it can be concluded that there was significant differences in the rearing performances among six strains of Samia ricini, Donovan. The seasonal variation also has a significant impact on these parameters. These study can proved to be helpful in evaluating best strain in terms of rearing performance and those strains can be utilized for commercial rearing or can be considered as promising parents in breeding programs.

Acknowledgement: Authors are grateful to the principal of Nowgong college for providing laboratory facility in the biotech-hub and Department of Botany to carry out experiments of the present study and also thankful to the faculty members of Biotech hub and Department of zoology of Nowgong college for providing help during this work. Author must offer sincere thankfulness to Dr. Hemen Deka, Assistant Professor of Gauhati University ,Department of Botany for his immense help in doing statistical work.

\section{References}

[1]. Chakravorty, R. and Neog, K.(2006). Food plants of eri silkworm (Samia ricini Donovan) their rearing performance and prospects for exploitation. Abst. of national workshop on eri food plants. Oct.11-12. pp. 1-27.

[2]. Debraj, Y., Sarmah, M.C., Dutta, R.N., Singh, L.S., Das, P.K. and Benchamin, K.V. (2001) Field trail of elite crosses of eri silkworm, philosamia ricini, Hutt, Indian Silk, 40 (2), 15-16.

[3]. Nagaraju, J. and Goldsmith, M.R. (2002) Silkworm genomics-progress prospects. Curr. Sci.83,415-425

[4]. Rahmathulla,V.K. and Hiromani, M.S.(2013)Influence of temperature and humidity on growth and development of silk gland of a bivoltine silkworm hybrid. Irnian journal of Entomology 3,24-29.

[5]. Ray, P.P., Rao T.V. and Dash,P. (2010) Comparative studies on rearing performance of some ecoraces of erisilkworm (Philosamia ricini $H$ ) in different seasons.

[6]. Sakar, B.N. (2013) A study on Eri silkworm Samia ricini Donovan ecoraces with special reference to seed production. Ph D thesis. Gauhati university.

[7]. Sen, R., Ahsan, M., Datta,R.K. (1999) induction of resistance to Bombyx mori nuclear polyhedrosis virus into susceptible bivoltine silkworm breed. Indian J. Sericulture 38:107-112.

[8]. Siddiqui, A.A., Saha, L.M., and Das ,P.K. (2000) Genetic variability and correlation studies of some quantitative traits in Eri silk worm. International journal of wild silkmoth and silk, 5,234-237.

[9]. Singh H.R., Unni, B.G., Neog, K. and Bhattacharya,A. (2011) Sodium dodecyl sulfate polyacrylamide gel electrophoresis and Random amplified Polymorphic DNA based genetic variation in Eri Silk worm Samia Cynthia ricini., Lepidoptera:Saturniidae. African Journal of Biotehnology, Vol(10)70. 15684-15690.

[10]. Wankhade, L.N., Barman, H.D., Manoj, M., Rai and Rathod, M.K.(2014) Evaluation of some promising strains of Eri silkworm , Samia ricini in climatic condition of Vidarbha Region of Maharastra. Indian J.Applied and pure Bio. Vol.29(2),247-253. 